\title{
FH - HES
}

Fachhochschule - Hautes Ecoles Spécialisées

\section{Simulated Moving Bed Chromatography - The Next Step in HPLC}

\author{
Thomas van Oordta ${ }^{\mathrm{a}}$ Edwin Bayliss ${ }^{\mathrm{b}}$, Thomas Netscher ${ }^{\mathrm{c}}$, Werner Bonrath ${ }^{\mathrm{c}}$, and Thomas Spielmann ${ }^{\mathrm{a}}$
}

\begin{abstract}
Simulated Moving Bed (SMB) technology, a continuous chromatographic separation process, is of increasing interest in the field of pharmaceuticals, fine chemicals, and biotechnology. The complexity of SMB asks for a deeper understanding of the mathematical design and physical adsorption processes, along with the practical training in chromatography and process engineering. This makes SMB a technology which is also suitable for educational purposes. The principle of SMB separation is described with a short introduction of its mathematical design for a simulation. A method of measuring the adsorption isotherms, which are crucial for a process simulation, is also discussed. As an example, the application of SMB to the separation of two groups of biologically important vitamin $\mathrm{E}$ compounds, i.e. tocopherols and tocotrienols from natural-source material is presented.
\end{abstract}

Keywords: Preparative chromatography · Simulated Moving Bed · Tocopherols · Tocotrienols · Vitamin E

\section{Introduction}

\subsection{SMB Chromatography}

SMB chromatography offers many advantages over conventional batch elution chromatography such as higher productivity due to continuous operation and an efficient entire use of the stationary phase as well as a reduction of solvent consumption. SMB is a further development of the True Moving Bed (TMB) process, where liquid and solid flow in opposite directions [1]. Both flows are pumped circularly back into the process (Fig. 1).

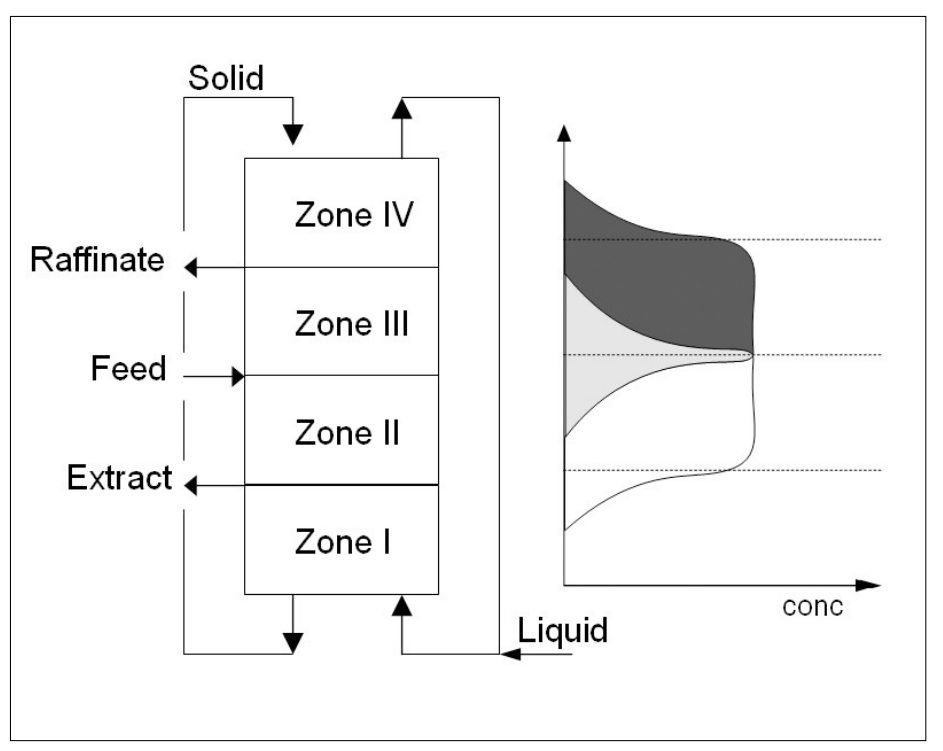

Fig. 1. Scheme of a True Moving Bed process with the corresponding concentration profile
${ }^{*}$ Correspondence: Prof. T. Spielmann ${ }^{a}$

Tel.: +4152267 7436

E-Mail: spl@zhwin.ch

aZurich University of Applied Sciences Winterthur Department of Chemistry and Biological Chemistry

PO Box 805

$\mathrm{CH}-8401$ Winterthur

bflowspek ag

Efringerstrasse 32

$\mathrm{CH}-4057$ Basel

'DSM Nutritional Products

Research and Development

PO Box 3255

$\mathrm{CH}-4002$ Basel
This allows a continuous fractionation of a binary system with the mixture being injected continuously. The more strongly retained product (extract) is distributed in zones II and III, moves downwards with the solid adsorbent stream and is completely desorbed in zone I leading to a pure extract stream. Correspondingly the less strongly retained product (raffinate) is separated from the extract in zones II and III leading to a pure raffinate stream due to complete adsorption in zone IV. The circulation of the solid adsorbent and abrasion of the particles make a TMB difficult to operate, which is why the SMB concept was introduced. The SMB technology simulates the movement of the solid phase by an appropriate switching sequence of several columns connected in series contrary to the liquid phase flow as shown in Fig. 2. 


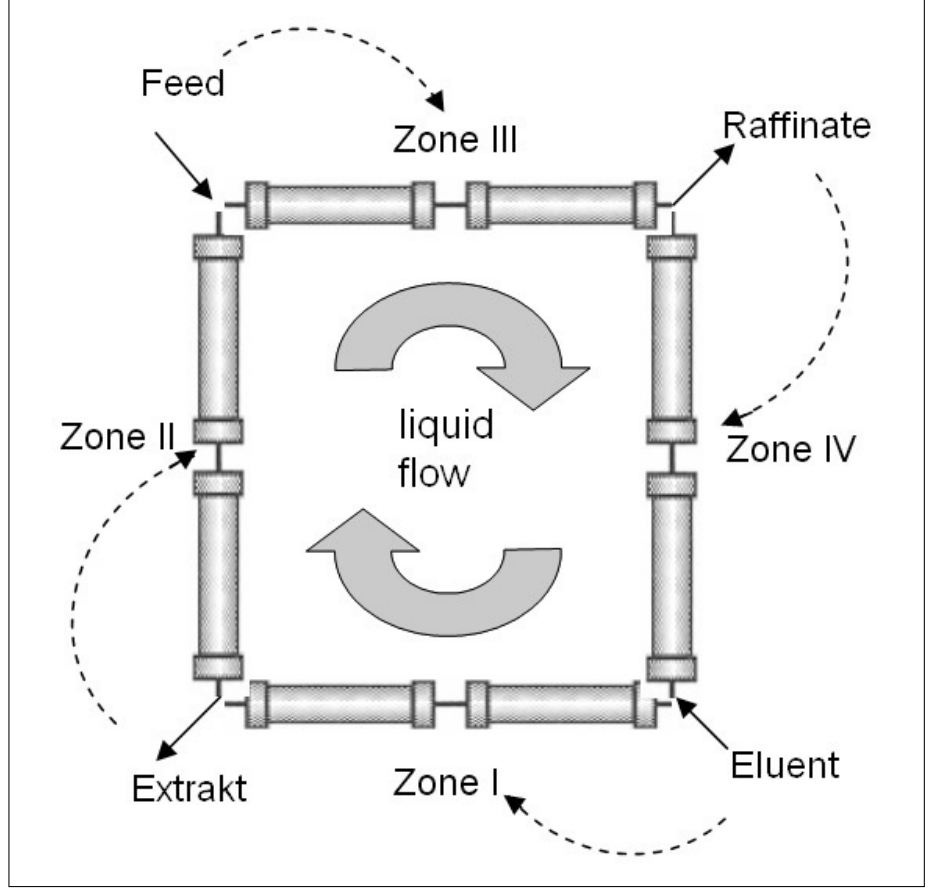

Fig. 2. Principle of the SMB system. The dashed lines indicate the switching sequence

\subsection{Adsorption Isotherms}

In case of a thermodynamic equilibrium, the adsorption isotherm defines the ratio of the concentration of a compound in the stationary phase $\boldsymbol{q}$ and in the liquid phase $c$ at a given temperature. Knowledge of the adsorption isotherms is essential to estimate appropriate operating parameters (e.g. switching time and flow rates in each zone). Many models try to characterize the functional relationship of the adsorption isotherms like the multi-Langmuir equation (Eqn. (1)) for $\boldsymbol{N}$ components where $\boldsymbol{q}$ refers to the equilibrium loading at a given concentration $c$. The saturation capacity of the adsorbent is $\boldsymbol{q}_{\max }$ and $\boldsymbol{K}$ refers to the ratio of the adsorption to desorption rate constant [2][3].

$$
q_{i}=q_{\max } \frac{c_{i} K_{i}}{1+\sum_{j=1}^{N} c_{j} K_{j}} \quad j=1 \ldots N
$$

A fast method to determine a large range of the adsorption isotherm starts from the following Eqn. based on standard mass equilibrium considerations [4]:

$$
t_{R}(c)=t_{0}\left(1+\left.\frac{1-\varepsilon}{\varepsilon} \frac{d q}{d c}\right|_{c}\right)
$$

This Eqn. shows the correlation of the retention time $\boldsymbol{t}_{R}$ to the hold-up time $\boldsymbol{t}_{0}$ of the column, the total porosity $\varepsilon$ and the equilibrium loading $\boldsymbol{q}$.

If the adsorption isotherm is of the Langmuir type the derivative of Eqn. (1) can be inserted for one component into Eqn. (2) [2].

$$
t_{R}=t_{0}\left(1+\frac{1-\varepsilon}{\varepsilon} \frac{q_{\max } K}{(1+K c)^{2}}\right)
$$

Now with an injection of a single highly concentrated sample into the column the parameters $\boldsymbol{q}_{\text {max }}$ and $\boldsymbol{K}$ can be easily determined by a nonlinear regression according to Eqn. (3).

This method requires a minimum of experimental effort but it is only suitable for a single component and detector calibration is necessary, however, many other methods to determine the adsorption isotherms are described [5].

\section{Group Separation of a Vitamin $E$ Extract}

As an example, the application of SMB to the separation of the compounds contained in a vitamin $\mathrm{E}$ extract from a natural source is described. Tocotrienols and tocopherols are the main components in naturally occurring vitamin E. Both groups of substances are very effective antioxidants and are structurally closely related [6]. Unlike the tocopherols, tocotrienols have three double bonds in the isoprenoid side chain. The $\left(2 R, 4^{\prime} R, 8^{\prime} R\right)$ configuration is found in naturally occurring tocopherols, and tocotrienols possess the $\left(2 R, 3^{\prime} E, 7^{\prime} E\right)$-configuration. The material obtained from palm oil used in this study also contains $\alpha$-tocomonoenol with $\left(2 R, 4^{\prime} R, 8^{\prime} S\right)-11^{\prime}, 12^{\prime}$ '-dehydro configuration [7] (Fig. 3).

The concentrations of tocotrienols and tocopherols vary widely among different vegetable oils such as coconut oil, palm oil and cereal grains such as oat, wheat, and barley [8]. Because of the interesting biological activity of vitamin E components, the preparative chromatographic isolation of tocotrienols and tocopherols, as one possibility for obtaining pure, single-component material, is of much interest for further investigations [9-11].

\subsection{Experimental}

\subsubsection{Chemicals and Reagents}

All solvents were HPLC grade and were purchased from Sigma-Aldrich (Buchs, $\mathrm{CH})$. The vitamin E extract was obtained from commercial palm oil residues, with GC specifications (quantitative wt $\%$ values) as follows: $\alpha$-tocopherol $10.9 \%, \beta$-tocopherol $0.5 \%, \gamma$-tocopherol $0.3 \%, \alpha-11^{\prime}, 12^{\prime}$-dehtocomonoenol $2.0 \%$, $\alpha$-tocotrienol $11.3 \%$, $\beta$-tocotrienol $2.2 \%, \gamma$-tocotrienol $11.0 \%$, $\delta$-tocotrienol $7.1 \%$ and residue of stearic, linoleic, and linolenic acid glyceride.

The tocopherol standards $\left(\left(2 R, 4^{\prime} R, 8^{\prime} R\right)\right.$ $\alpha$-tocopherol, $\quad\left(2 R, 4^{\prime} R, 8^{\prime} R\right)-\beta$-tocopherol, $\left(2 R, 4^{\prime} R, 8^{\prime} R\right)$ - $\gamma$-tocopherol and $\left(2 R, 4^{\prime} R, 8^{\prime} R\right)$ $\delta$-tocopherol) and tocotrienol standards $\left(\left(2 R, 3^{\prime} E, 7^{\prime} E\right)-\alpha\right.$-tocotrienol, $\quad\left(2 R, 3^{\prime} E, 7^{\prime} E\right)-$ $\beta$-tocotrienol, $\quad\left(2 R, 3^{\prime} E, 7^{\prime} E\right)-\gamma$-tocotrienol, $\left(2 R, 3^{\prime} E, 7^{\prime} E\right)$ - $\delta$-tocotrienol) were obtained by conventional (batch) silica gel column chromatographic isolation from natural-source material.

\subsubsection{Chromatography}

SMB chromatography was performed on a Knauer SMB CSEP 9116 Pilot Unit consisting of eight Knauer Eurospher C18 $15 \mu \mathrm{m}$ reversed phase columns (120/8 mm diameter). Analytical experiments were performed on a reversed phase MachereyNagel Nucleosil C18 5 um column (250/4.8 mm diameter) with a Spectroflow 783 (ABI Analytical Kratos Division) UV detector $(296 \mathrm{~nm})$. Data acquisition and processing were made using a Geminyx Chromatography Data System. Samples were injected using a $20 \mu \mathrm{l}$ loop for analytical HPLC and a $200 \mu \mathrm{l}$ loop to determine the adsorption isotherms at a flow rate of $2.0 \mathrm{ml} / \mathrm{min}$.

The mobile phase for the group separation of tocopherols from tocotrienols consisted of acetonitrile:methanol 95:5.

\section{Results and Discussion}

Fig. 4 shows a typical example of the elution order of tocopherols and tocotrienols. The less polar but more saturated tocopherols are retained longer in the column, as expected for a reversed-phase system [11]. The correct set-up of the flowrates in zones II and III, taking into account the 
<smiles>[R20][R6][R6](=O)O[Na]</smiles>

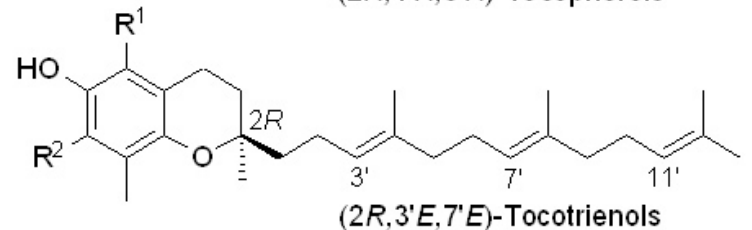

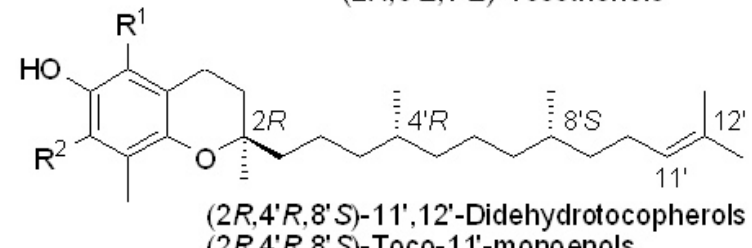
$\left(2 R, 4^{\prime} R, 8^{\prime} S\right)$-Toco-11'-monoenols

\begin{tabular}{c|ll} 
Homologue & $\mathrm{R}^{1}$ & $\mathrm{R}^{2}$ \\
\hline$\alpha$ & $\mathrm{CH}_{3}$ & $\mathrm{CH}_{3}$ \\
$\beta$ & $\mathrm{CH}_{3}$ & $\mathrm{H}$ \\
$\gamma$ & $\mathrm{H}$ & $\mathrm{CH}_{3}$ \\
$\delta$ & $\mathrm{H}$ & $\mathrm{H}$
\end{tabular}

Fig. 3. Chemical structures of tocopherols, tocotrienols and tocomonoenols

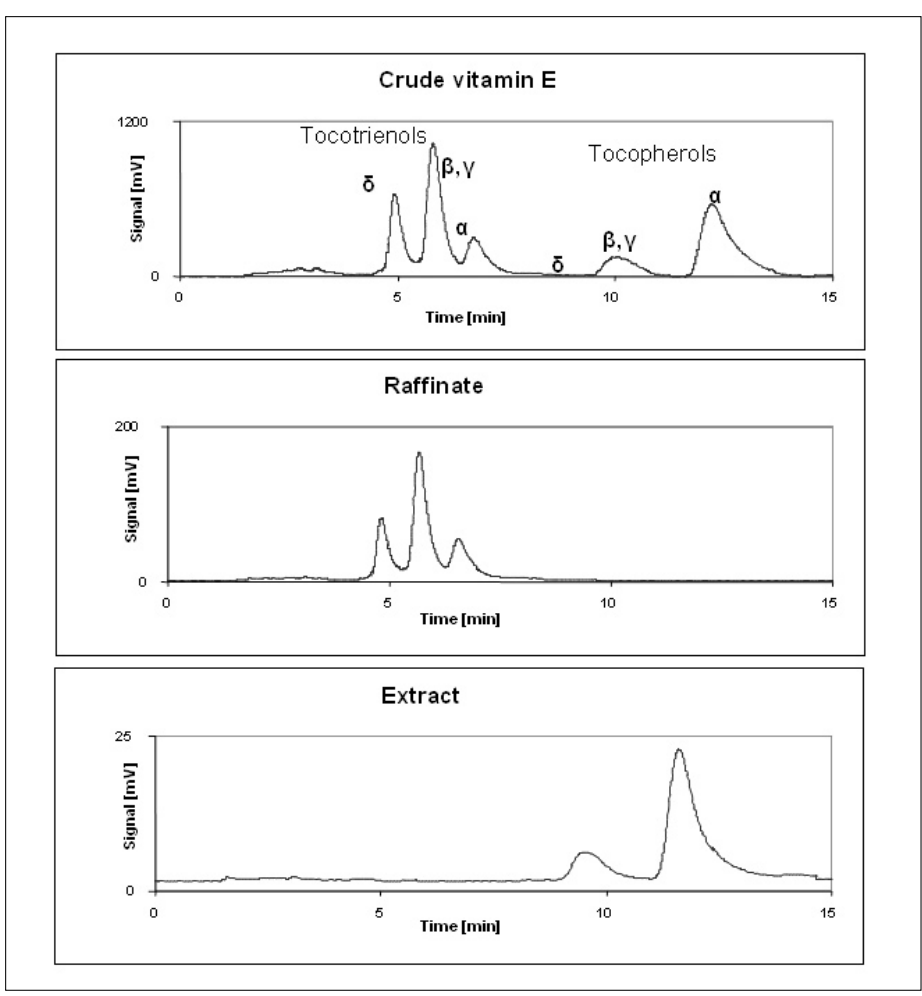

Fig. 4. HPLC chromatograms of the crude Vitamin E and the SMB raffinate and extract flow adsorption isotherms of $\alpha$-tocotrienol and $\delta$ tocopherol, is critical for the success of the separation. The less strongly retained $\alpha$-tocotrienol moves with the liquid stream into zone $\mathrm{IV}$, the more strongly retained $\delta$-tocopherol moves with the solid stream into zone I. The liquid stream exiting from zone IV is recycled into zone I while an appropriate flow rate in zone IV ensures that no tocotrienols contaminate the extract stream. Correspondingly the appropriate high flow rate in zone I guarantees that no tocopherol enters zone IV.

This separation yielded pure extract and raffinate streams with less than $0.5 \%$ contamination of tocopherols in the raffinate flow and tocotrienols in the extract flow respectively and an eluent consumption of $318 \mathrm{ml} / \mathrm{g}$ crude and the productivity of $32 \mathrm{~g}$ crude/day. Furthermore several tocotrienols from the raffinate stream could be isolated by another SMB process (data not shown) [12].

\section{Conclusion}

Since SMB plants for lab-scale production are commercially available this technology can be a major enrichment for education in universities. SMB technology includes mathematical design, simulation processes and work-experience in preparative and analytical chromatography and can be widely used in separation of bioactive compound, pharmaceuticals, fine chemicals and so forth [13][14]. Therefore, for the Zurich University of Applied Sciences Winterthur, SMB is a beneficial technology which applies to many fields of research.

The principal objective of the SMB plant used at the Zurich University of Applied Sciences Winterthur is to develop and optimize separation processes rather than sheer production. This includes allowing students to conduct research for their diploma thesis.

As an example, the application of SMB to the separation of compounds contained in a natural-source vitamin E extract could successfully be carried out [12]. Furthermore an enantioselective separation of $\beta$-blocker enantiomers (propranolol) on the same SMB plant was studied in another work [15]. The homogeneity of packed columns, being responsible for identical retention time behavior of the eluates, is crucial for the development of a process by using software simulating with identical column properties. In addition maintenance of the liquid flow rates in each zone during the entire time of production may pose a challenge.

\section{Acknowledgements}

The authors wish to thank Silvia Studer who contributed to the separation data, Knauer $\mathrm{GmbH}$ Berlin for donation of the HPLC columns and the School of Engineering of the Zurich University of Applied Sciences Winterthur for the financial support.

Received: February 1, 2006

[1] M. Schulte, K. Wekenborg, W. Wewers, in 'Preparative Chromatography', Ed. H.
Schmidt-Traub, Wiley-VCH, Dortmund 2005, p. 173.

[2] H. Kniep, A. Seidel-Morgenstern, 'Design and Simulation of Simulated Moving Beds', SMB-Guide 1.1 Manual, 1997.

[3] A. Gentilini, C. Migliorini, M. Mazzotti, M. Morbidelli, J. Chromato. A 1998, 805, 37-44.

[4] D. Tondeur, H. Kabir, L.A. Lou, J. Granger, Chem. Eng. Sci. 1996, 51, 3781-3799.

[5] M. Michel, A. Epping, A. Jupke, in 'Preparative Chromatography', Ed. $\mathrm{H}$. SchmidtTraub, Wiley-VCH, Dortmund 2005, p. 215.

[6] T. Netscher, Chimia 1996, 50, 563-567.

[7] A. Matsumoto, S. Takahashi, K. Nakano, S. Kijima, Yukagaku 1995, 44, 593-597 (CA 123:336445); G. Schiefer, R.K. Müller, H. Schneider, M. Umiker, T. Netscher, Chimia 1999, 53, 359.

[8] H. Crawley, in 'The Technology of Vitamins in Food', Blackie Academic \& Professional, Chapman \& Hall Inc., Glasgow, 1993, Chap. 2, p. 19.

[9] F.J. Rupérez, D. Martin, E. Herrera, C. Barbas, J. Chromato. A 2001, 935, 45-69.

[10] Tai-Sun Shin, J.S. Godber, J. Chromato. A 1994, 678, 49-58.

[11] S.L. Abidi, J. Chromato. A 2000, 881, 197216.

[12] S. Studer, 'Simulated Moving Bed Chromatography', Diplomarbeit ZHW, 2005.

[13] D.W. Guest, J. Chromato. A 1997, 760 159-162.

[14] S. Imamoglu, Advances in Biochemical Engineering/Biotechnology 2002, 76, 211231.

[15] T. van Oordt, 'Simulated Moving Bed Chromatography', Diplomarbeit ZHW, 2004. 